\title{
A Dense GNSS Meteorological Network for Observing Deep Convection in the Amazonian Region
}

\author{
David K.Adams \\ Universidade do Estado do Amazonas \\ Rui M. S. Fernandes \\ Universidade da Beira Interior \\ E. Robert Kursinski \\ University of Arizona \\ Jair M. Maia \\ Universidade do Estado do Amazonas
}

Luiz F. Sapucci

Centro de Previsão de Tempo e Estudos Climáticos

Luiz A. Machado

Centro de Previsão de Tempo e Estudos Climáticos

Ícaro Vitorello

Instituto Nacional de Pesquisas Espaciais

João Galera

Universidade Estadual Paulista

Kirk L. Holub

National Oceanic and Atmospheric Administration

Seth I. Gutman

National Oceanic and Atmospheric Administration

Naziano Filizola

Universidade Federal do Amazonas

Richard A. Bennett

University of Arizona

Draft version for submission to Atmospheric Science Letters

June, 2010 


\section{1) INTRODUCTION}

\section{ABSTRACT}

A sizeable literature has focused on the complex relationship between water vapor variability and deep convection in the tropics (see Sherwood et al., 2009 for a review). Unlike higher latitudes, rotational dynamical constraints are weak and precipitation-induced heating perturbations are rapidly communicated over great distances (Bretherton and Smolarkiewicz 1989; Mapes 1997). Water vapor, on the other hand, is highly variable in space and time; its spatial distribution depending on much slower advective processes above the boundary layer and on deep convection itself. Furthermore, deep convection, through vertical transport of water vapor and evaporation of cloud droplets and hydrometeors, serves as the free tropospheric water vapor source. And deep convection is itself sensitive to the free tropospheric humidity distribution through local moistening of the environment which favors further deep convection; a positive feedback (Tompkins 2001a, 2001b; Grabowski and Moncrieff 2004; Holloway and Neelin 2009).

Water vapor fields also play a role in deep convection through the generation of parcel thermodynamic energy, namely, convective available potential energy (CAPE). CAPE essentially depends on boundary layer moisture, but is also sensitive to parcel level of origin, thermodynamic path, ice phase inclusion, and to free tropospheric humidity through virtual temperature effects (Williams and Rennó 1993, Adams and Souza 2009). Traditional "quasi-equilibrium" convective parameterizations generally employ CAPE as both a trigger of and closure for deep convection. In continental tropical regions, these parameterizations poorly represent the diurnal cycle, convecting too early and too often, altogether skipping the shallow-to-deep convection transition (Betts and Jakobs 2002b; Grabowski et al. 2006; Adams et al. $2009^{1}$ ). The timing and quantity of upper-tropospheric heating with these overactive parameterizations are therefore unrealistic and have consequences for model dynamics and cloud/radiation fields (Betts and Jakobs 2002b). Given that free tropospheric humidity is critical in modulating the transition from shallow-to-deep convection (Derbyshire et al. 2004, Wu et al. 2009), convective parameterizations should be sensitive to tropospheric humidity through adequately representing entrainment of environmental air (Kuang and Bretherton 2006).

The formation of cumulonimbus clouds into lines and clusters is even tied to the humidity distribution. Under conditions of weak dynamical forcing, cloud-resolving models have indicated that convective downdrafts/cold pools act prominently during the shallow-to-deep transition and mesoscale organization (Tompkins 2001b, Khairoutdinov and Randall 2006). The strength of convective downdrafts and cold pool formation are strongly linked to vertical humidity profiles through entrainment and evaporatively driven negative buoyancy acceleration below cloud base (Tompkins 2001a, 2001b). Nevertheless, cold pool formation and mesoscale organization, in general, are mostly absent from convective parameterizations (however, see Grandpeix and Lafore 2010). Below synoptic scale, interactions between individual cumulonimbus clouds, organized convective complexes and associated mesoscale circulations can cover several model grid cells, muddying the separation of largescale forcing (grid-scale) from convective response (subgrid-scale) (Mapes 1997; Moncrieff 2004; Moncrieff and Liu 2006). Most "quasi-equilibrium" parameterizations, however, retain this arbitrary large-scale/convective-scale separation even though it most likely holds only from the synoptic-scale to the entire deep tropics (Mapes 1997; Rennó and Ingersoll 1996; Adams and Rennó 2003).

\footnotetext{
${ }^{1}$ An English translation available upon request.
} 
From the above discussion, the complex multi-scale interactions/feedbacks between deep convection/humidity are obviously exceedingly difficult to unravel and represent in large-scale models. To gain insight into convective/humidity interactions processes at the mesoscale $(\sim 100 \mathrm{~km})$ and below requires observations on the order of minutes and kilometers. Presently, no such mesoscale meteorological network exists in the equatorial continental region. In what follows, we motivate, present preliminary results, and define the specific goals for the embryonic, dense GNSS meteorological network in the center of Amazon Basin. Briefly, this network is designed to probe water vapor/convection interactions with emphasis on the shallow-to-deep convection transition and mesoscale organization. We overview the variables derived from GNSS meteorological techniques, describe the dense network and provide some initial results relevant for the network's organization and identification of convective events. The paper concludes with a summary of the additional goals for the network.

\section{2) AMAZON DENSE GNSS NETWORK: DESCRIPTION}

In the Amazon, important, but temporally limited, field campaigns have explored aspects of deep convection such as the diurnal cycle, the morphology of mesoscale complexes and tropical squall line formation and propagation (e.g., WETAMC, TRMM/LBA, see Silva Dias et al. 2002). We propose the development of a long-term ( $>1$ year), high-resolution meteorological network comprised of GNSS receivers and surface meteorological stations around Manaus, in the central Amazon Basin.

\section{a) GNSS ground-based meteorology}

For well over a decade GNSS ground-based meteorology has provided all weather, relatively inexpensive, high frequency ( 30 minutes), accurate measurements of atmospheric water vapor (for space-based occultation technique, see Kursinski et al., 2000). The range of applications of GNSS meteorological data have been wide ranging from assimilation into NWP models (Gutman and Benjamin 2001), meteorological case studies (Seko et al. 2004, Champollion et al. 2009), water vapor transport (Kursinski et al., 2008), and even atmospheric stability (De Haan 2006). The principal variable calculated is PWV

1) $P W V=\frac{1}{g \rho_{w}} \int_{p_{t}}^{p_{s}} q \frac{d p}{g}$

derived from water vapor induced delays in the radio signals from the satellite to the ground-based receiver (see Bevis et al., 1992). GNSS PWV accuracy is on the order of 1 to 2 millimeters (Duan et al. 1996, Sapucci et al., 2007).

More generally, PWV relates to the water conservation equation per unit area as follows,

2) $\frac{\partial P W V}{\partial t}+\partial / \partial t \int_{p_{t}}^{p_{s}} q_{e} \frac{d p}{g}+\nabla \cdot \int_{p_{t}}^{p_{s}} q \boldsymbol{V} \frac{d p}{g}=E-P$

In both Equations 1 and 2, the variables have their typical meteorological meanings with the subscript $\mathrm{s}$ for surface and $\mathrm{t}$ for top of the atmosphere and $\mathrm{V}$, the horizontal wind vector, $P_{w}$ is liquid water density. Prior to precipitation (ignoring local evaporation, E, and horizontal fluxes of condensed water, qc), the time-rate-of-change of PWV is determined by column water vapor convergence and cloudy air 